\title{
Monolayers of Cholesterol and Cholesteryl Stearate at the Water/Vapor Interface: A Physico-Chemical Study of Components of the Meibum Layer
}

\author{
Ramón G. Rubio ${ }^{1,2, *(\mathbb{D})}$, Eduardo Guzmán ${ }^{1,2, *(\mathbb{C})}$, Francisco Ortega ${ }^{1,2}$ and Libero Liggieri ${ }^{3}(\mathbb{D}$ \\ 1 Departamento de Química Física, Facultad de Ciencias Químicas, Universidad Complutense de Madrid, \\ Ciudad Universitaria s/n, 28040 Madrid, Spain; fortega@quim.ucm.es \\ 2 Instituto Pluridisciplinar, Universidad Complutense de Madrid, Paseo de Juan XXIII 1, 28040 Madrid, Spain \\ 3 Istituto di Chimica della Materia Condensata e di Tecnologie per l'Energia-U.O.S. Genova, \\ Consiglio Nazionale delle Ricerche, Via Marini 6, 16149 Genova, Italy; libero.liggieri@ge.icmate.cnr.it \\ * Correspondence: rgrubio@quim.ucm.es (R.G.R.); eduardogs@quim.ucm.es (E.G.); \\ Tel.: +34-91-394-4123 (R.G.R.); +34-91-394-4107 (E.G.)
}

check for

updates

Citation: Rubio, R.G.; Guzmán, E.; Ortega, F.; Liggieri, L. Monolayers of Cholesterol and Cholesteryl Stearate at the Water/Vapor Interface: A

Physico-Chemical Study of Components of the Meibum Layer. Colloids Interfaces 2021, 5, 30. https:/ / doi.org/10.3390/colloids5020030

Academic Editors: Giuseppe Loglio and Volodymyr I. Kovalchuk

Received: 30 April 2021

Accepted: 19 May 2021

Published: 20 May 2021

Publisher's Note: MDPI stays neutral with regard to jurisdictional claims in published maps and institutional affiliations.

Copyright: (c) 2021 by the authors. Licensee MDPI, Basel, Switzerland. This article is an open access article distributed under the terms and conditions of the Creative Commons Attribution (CC BY) license (https:// creativecommons.org/licenses/by/ $4.0 /)$.

\begin{abstract}
Langmuir monolayers containing different amounts of cholesterol and cholesteryl stearate were studied at two different temperatures $\left(24{ }^{\circ} \mathrm{C}\right.$ and $\left.35^{\circ} \mathrm{C}\right)$. The main goal was to contribute towards the understanding of how the variations in the chemical composition may affect the physicochemical properties of these specific lipid monolayers. The model mixture was chosen considering that cholesteryl esters are present in cell membranes and some other biological systems, including human tear lipids. Therefore, an investigation into the effect of the lipid monolayer composition on their interfacial properties may elucidate some of the fundamental reasons for the deficiencies in cell membranes and tear film functioning in vivo. The experimental results have shown that the molar ratio of the mixture plays a crucial role in the modulation of the Langmuir film properties. The condensing effects of the cholesterol and the interactions between the lipids in the monolayer were the main factors altering the monolayer response to dilatational deformation. The modification of the mixture compositions leads to significant changes in the Langmuir films and the mechanical performance, altering the ability of the monolayer to reduce the surface tension and the viscoelastic properties of the monolayers. This suggests that subtle modifications of the biomembrane composition may significantly alter its physiological function.
\end{abstract}

Keywords: Langmuir monolayers; dilational rheology; cholesterol; cholesteryl stearate

\section{Introduction}

Cholesteryl esters and cholesterol together with wax esters are counted among the most important components of the fatty secretion of the meibomian glands [1-3], driving the decrease in the surface tension and contributing to the Marangoni-driven homogeneous spreading of the tears upon blinking [4-6]. Furthermore, they also contribute to counteracting the film thinning by retarding the water evaporation, and by lubricating and stabilizing the tear film [7-10].

The organization of the lipids on the meibum film occurs in such a way that the van de Waals interactions between the hydrophobic regions of the lipid molecules and the hydrogen bonds between different polar groups, mainly ester and hydroxyl ones, are maximized [11]. This results in a liquid crystalline phase at a low temperature and a gel phase at a higher temperature, where the side chains of the cholesterol esters are highly interdigitated, and the packing between the adjacent steroid nuclei and carbonyl moieties is maximized [12]. Furthermore, the interaction of meibum with different polar phospholipids and proteins forming the adjacent tear film lipid contributes to the preservation of the stability and physiological function of tear film [13-15]. 
Different factors can influence the stability and physiological function of tear film, including autoimmune, environmental, hormonal or toxic factors. These lead to different alterations in the structural order of the lipid molecules and the mechanical properties of meibum, which can result in different pathological states [16-18]. This makes it necessary to explore the origin of such pathological states and seek potential therapeutic approaches for minimizing its impact on human health [19].

It is commonly accepted that the origin of most of the physiological deficiencies on biological structures formed by lipids, such a meibum films, are associated with structural changes, which reduce its stability $[20,21]$. This leads to a situation in which the ability of the lipid layers for reducing the surface tension and their rheological properties are significantly worsened $[9,10,22,23]$. This has been commonly rationalized in terms of compositional changes of the secretion of the meibomiam gland [24]. However, many aspects regarding the correlations existing between the composition, structure and function of lipid structures are still a matter of an intense debate [25]. This appears to be very important because it has been reported that a subtle modification in the concentration of very specific lipids may affect significantly the development of ocular diseases [26]. Therefore, the understanding of the effect of the composition of the lipid layer on the interfacial properties of the meibomian fatty secretion appears as a very relevant issue to shed light on some of the most fundamental aspects related to the emergence of different ocular diseases [27]. This can be analyzed from a very simple perspective, using Langmuir monolayers of cholesterol and cholesteryl stearate, which can be considered a reasonably simple model, accounting for an important part of the meibum composition. In particular, the change on the content of cholesterol and cholesteryl stearate in the meibomian film may affect its integrity, which may increase the rate of water evaporation, altering the functionality of the whole tear film [26]. Furthermore, considering that the meibum is not in equilibrium, but undergoes numerous mechanical perturbations from its formation until its renewal upon blinking, it seems also convenient to measure the dilational modulus of elasticity and viscosity under dynamic conditions. Bearing in mind that a typical blinking period is around $5 \mathrm{~s}$ [28], it may be convenient to perform measurements at frequencies close to $0.1 \mathrm{~Hz}$, even though it should not be forgotten that the real disturbance of the tear fluid does not respond to a periodic sinusoidal deformation. Furthermore, the characterization of the equilibrium properties of the lipid monolayers is also essential to draw conclusions about the dynamic properties. It should be noted that the use of Langmuir monolayers as models allows focusing our research to the apolar sublayer of the tear film. The use of this well-controlled model allows a careful monitoring of the rheological properties and the specific interactions between the components within the lipid layer [19].

\section{Materials and Methods}

\subsection{Chemicals}

Cholesterol $(\mathrm{CH})$ and Cholesteryl stearate (CS) were purchased from Sigma (Saint Louis, MO, USA) at 99\% purity and were used without further purification.

Chloroform (CHROMASOLV ${ }^{\mathrm{TM}}$, for High Performance Liquid Chromatography, stabilized with ethanol) purchased from Sigma-Aldrich (Saint Louis, MO, USA) was used for preparing the spreading solutions.

Ultrapure deionized water used for cleaning and solution preparation was obtained by a multicartridge purification system AquaMAX ${ }^{\mathrm{TM}}$-Ultra 370 Series. (Young Lin Instrument Co., Ltd., Gyeonggi-do, South Korea), presenting a resistivity higher than $18 \mathrm{M} \Omega \mathrm{cm}$, and a total organic content lower than 6 ppm.

\subsection{Preparation of Lipid Monolayers}

The lipid monolayers were prepared at the water/vapor interface by dropping controlled volumes of lipid mixtures from its solution in chloroform (concentration about $1 \mathrm{mg} / \mathrm{mL}$ ) using a high-precision Hamilton syringe (Hamilton Company, Reno, NV, USA). This methodology ensures the control of the interfacial density of lipid upon solvent evap- 
oration. Once monolayers are obtained, $30 \mathrm{~min}$ are waited before starting the experiments to ensure the complete evaporation of the solvent.

Experiments were performed at two different temperatures: $24.0 \pm 0.1{ }^{\circ} \mathrm{C}$ and $35.0 \pm 0.1^{\circ} \mathrm{C}$, with the latter being the average temperature of the cornea of human eyes [29].

\subsection{Methods}

The Langmuir monolayers were studied using a through Nima model 702 (Nima Technologies, Ltd., Coventry, UK), equipped with two Delrin ${ }^{\circledR}$ barriers allowing for symmetric compression/expansion of the free liquid surface. The total surface area of the Teflon trough is $700 \mathrm{~cm}^{2}$. The surface tension, $\gamma$, was measured using a force balance fitted with a paper Wilhelmy plate (Whatman CHR1 chromatography paper, effective perimeter $20.6 \mathrm{~mm}$, supplied by Sigma Aldrich, St. Louis, MO, USA), ensuring a zero contact angle. The surface pressure, $\Pi$, is obtained as the difference between the surface tension of the pure water/vapor interface $\gamma_{w}$ and $\gamma$, i.e., $\Pi=\gamma_{w}-\gamma$.

The quasi-equilibrium isotherms for the monolayers were obtained measuring the surface pressure as the interfacial area available for the monolayer, $\mathrm{A}$, is reduced at a fixed compression velocity of $1 \mathrm{~mm} / \mathrm{min}$. This compression rate allows minimizing any undesired non-equilibrium effects during the determination of the isotherms [30,31].

The Langmuir trough also enables the study of the dilational rheology of the lipid monolayers using the oscillatory barrier method. A detailed description of this method can be found elsewhere [32-36]. The oscillatory barrier method allows evaluating the modulus of the complex dilational viscoelasticity $\mathrm{E}=\Delta \gamma /(\Delta \mathrm{A} / \mathrm{A})$, i.e., the variation, of the surface tension $\gamma$ as result of a harmonic change of the interfacial area at a controlled frequency $v$ (in a range of frequencies from $10^{-3}$ to $0.15 \mathrm{~Hz}$ ), with this change on the interfacial area being defined as

$$
A(\mathrm{t})=\mathrm{A}_{0}+\Delta \mathrm{A} \sin (2 \pi v \mathrm{t})
$$

The change of the interfacial area (strain) leads to a stress response $\Delta \Pi=\Pi_{0}-\Pi(t)$, which is defined as the change in surface pressure between the reference state $\Pi_{0}$ and the instantaneous value of the surface pressure $\Pi(\mathrm{t})$. For small amplitude deformations, i.e., for deformations within the linear regime, the stress response also follows a sinusoidal profile with the same frequency as the deformation

$$
\Pi(\mathrm{t})=\Delta \Pi \sin (2 \pi v \mathrm{t}+\phi)
$$

with $\phi$ being a phase shift accounting for a possible delay of the stress response (surface pressure change) in relation to the strain (area deformation). For systems with a linear response, the stress can be considered proportional to the deformation $u(t)=\Delta A / A_{0}$ (elastic term) and to the rate of deformation $\mathrm{du}(\mathrm{t}) / \mathrm{dt}$ (viscous term), which allows one to write the stress as

$$
\Pi(\mathrm{t})=\epsilon^{\prime} \mathrm{u}(\mathrm{t})+\kappa\left(\frac{\mathrm{du}(\mathrm{t})}{\mathrm{dt}}\right)
$$

with $\varepsilon^{\prime}$ and $\kappa$ being the dilational elasticity and viscosity, respectively. Considering the definition given by Equation (3) and assuming a generic harmonic perturbation, the complex dilational viscoelasticity, $\varepsilon$, can be defined as

$$
\varepsilon=\varepsilon l+2 \pi v \kappa \mathrm{i}
$$

with $i=\sqrt{-1}$, so that $E=|\varepsilon|$. The analysis of the curves corresponding to the strain and stress in terms of Equations (1) and (2) provide information about their amplitudes and the phase shift, enabling the calculation of the dilational viscoelasticity.

A Brewster Angle Microscope Nanofilm EP3 from Accurion Gmbh (Göttingen, Germany) equipped with a solid state laser $(\lambda=532 \mathrm{~nm})$ and coupled to the Langmuir was used to obtain information about interfacial textures, i.e., the lateral organization of lipids at the interface. 


\section{Results and Discussion}

3.1. Equilibrium Behavior of Langmuir Monolayers of Pure Componentes at $24^{\circ} \mathrm{C}$ : Cholesterol and Cholesteryl Estearate

This work is focused on the analysis of the effect of the composition on the interfacial properties of Langmuir monolayers of binary mixtures containing $\mathrm{CH}$ and $\mathrm{CS}$. However, any physical meaningful discussion requires the analysis of the interfacial behavior of the pure lipids as a preliminary step. Figure 1a shows the surface pressure-area per molecule isotherms $\left(\Pi-\mathrm{A}_{\mathrm{m}}\right.$ ) for monolayers of $\mathrm{CH}$ and $\mathrm{CS}$ spread at the water/vapor interface, where $A_{m}=A / N$, with $N$ being the number of molecules initially spread at the water/vapor interface.
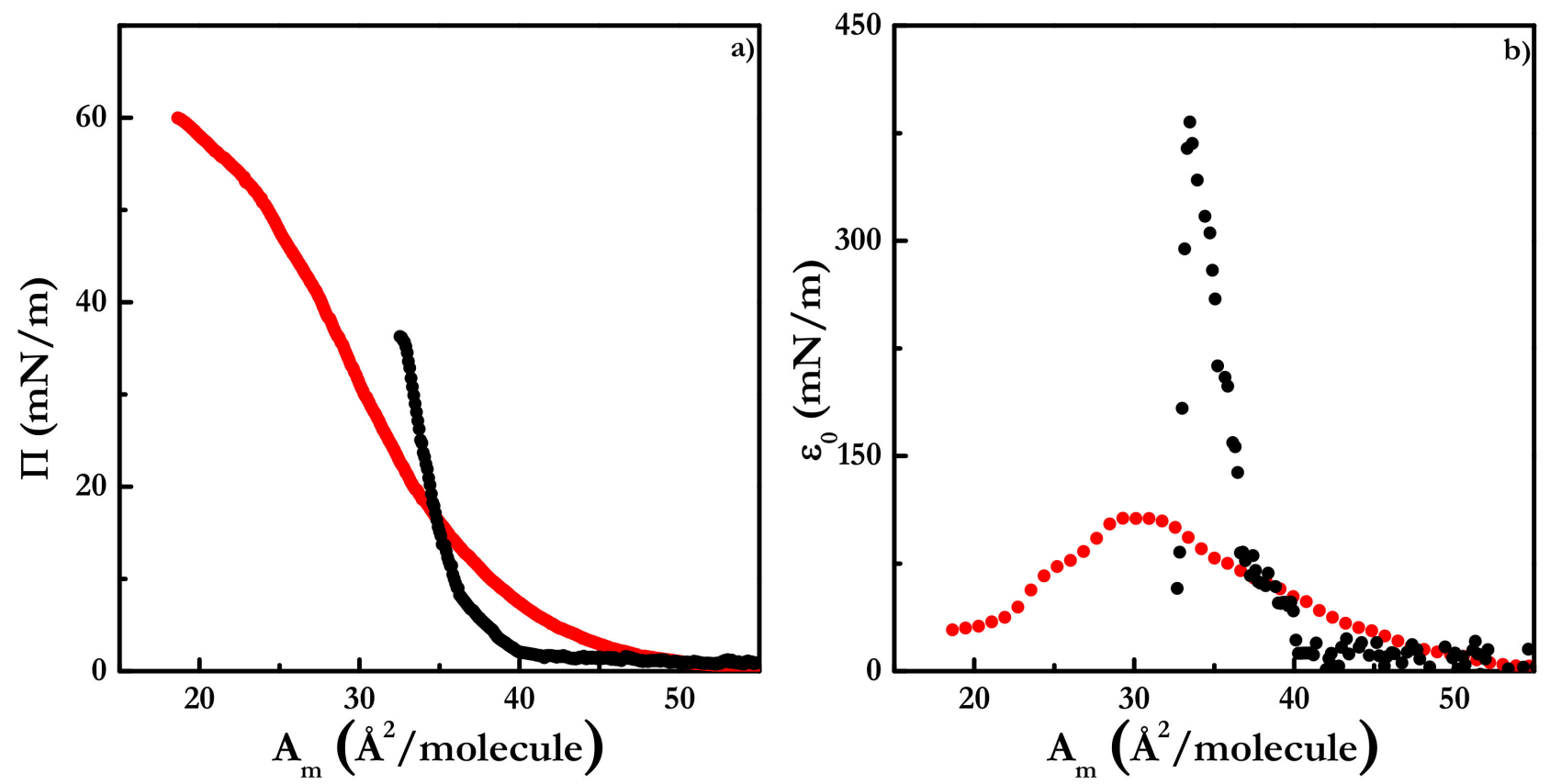

Figure 1. (a) Surface pressure-area per molecule of isotherms for Langmuir monolayers of $\mathrm{CH}$ and $\mathrm{CE}$ spread at the water/vapor interface at $24{ }^{\circ} \mathrm{C}$. (b) Quasi-static dilational elasticity, $\varepsilon_{0}$, dependences on the surface pressure, $\Pi$, for Langmuir monolayers of $\mathrm{CH}$ and $\mathrm{CE}$ spread at the water/vapor interface at $24^{\circ} \mathrm{C}$. In both panels: $\mathrm{CH}(\bullet)$ and $\mathrm{CS}(\bullet)$.

The isotherms obtained for $\mathrm{CH}$ and $\mathrm{CS}$ spread at the water/vapor interface agree with those previously reported in the literature [37-42]. For $\mathrm{CH}$, the isotherms show a large region at the area per molecule above $45 \AA^{2}$ where the monolayer presents almost negligible surface pressure values, i.e., it corresponds to a gas phase. A further compression results in a sudden increase in the surface pressure until the collapse. Therefore, it can be expected that upon compression, $\mathrm{CH}$ molecules start to reorient at the interface to maximize the lateral van der Waals interactions between their sterol rings. This results in the formation of close packed monolayers with the molecules oriented perpendicularly to the water/vapor interface, resulting in the formation of a solid-like layer with a high stiffness [43]. On the other side, the isotherm of the CS presents the typical feature of an expanded-like monolayer in which the surface pressure increases continuously till a collapse surface pressure slightly above $55 \mathrm{mN} / \mathrm{m}$. This behavior may be due to the presence of a certain steric hindrance for the molecular packing, which weakens the van der Waals interactions between the molecules at the interface [44,45].

Further insights on the organization of the lipid molecules at the interface and the strength of their interactions are obtained from the quasi-static dilational elasticity obtained from the isotherm as

$$
\varepsilon_{0}=-\mathrm{A}\left(\frac{\partial \Pi}{\partial \mathrm{A}}\right)_{\mathrm{t}}
$$


The quasi-static dilational elasticity provides important information on the energy stored for the monolayer upon continuous compression, and its value is related to the monolayer rigidity that, in turn, carries information on the packing of the molecules at the interface. Figure $1 \mathrm{~b}$ shows the area per molecule dependences of the quasi-static dilational elasticity for $\mathrm{CH}$ and CS. CH monolayers at the water/vapor interface presents a steep increase in the quasi-static dilational elasticity with the compression degree, reaching values above $400 \mathrm{mN} / \mathrm{m}$, and then dropping upon the monolayer collapse. This confirms the role of the cohesive van der Waals interactions existing in the monolayer, which results in the formation of a close-packed solid-like film, as suggested by the $\Pi-\mathrm{A}_{\mathrm{m}}$ isotherm. For the case of the $\mathrm{CS}$, the values of $\varepsilon_{0}$ are smaller than for $\mathrm{CH}$ monolayers, which agrees with the above discussion. Therefore, it is possible to assume that CS results in the formation of liquid-like monolayers [46], where $\varepsilon_{0}$ initially increases with the compression up to reach a maximum for a packing equivalent to a $\Pi$ value around $35 \mathrm{mN} / \mathrm{m}$, and then $\varepsilon_{0}$ drops towards a value close to zero as the collapse is approached. It should be noted that the large maximum value of $\varepsilon_{0}$ for CS monolayers is compatible with the hypothetical surface pressure value associated with the monolayer-bilayer transition $[47,48]$.

\subsection{Equilibrium Behavior of Langmuir Monolayers of Cholesterol-Cholesteryl Estearate Mixtures at $24^{\circ} \mathrm{C}$}

It has been mentioned above that a dysfunctional meibomian film may be the result of a change in packing of the lipid layer due to changes in the composition of the oily secretion of the meibomian gland. It is true that the stability of meibomian film at the water surface requires the presence of polar lipids for ensuring its stability. However, non-polar lipids such as those used here as a model system may affect the integrity of meibomiam film and its physiological function [26]. Therefore, it may be interesting to analyze how subtle changes in the composition of model lipid mixtures formed by $\mathrm{CH}$ and CS may modify some of their interfacial properties with relevance for their physiological performance. This may be analyzed using Langmuir monolayers combining both lipids in different compositions, even though it should be stressed that the extrapolation of the results obtained using a rough model to the real biophysical situation should be made carefully, because the tear film is not a truly 2D system, presenting a multi-lamellar structure (about $100 \mathrm{~nm}$ on thickness) with a high structural and chemical complexity [49]. Nevertheless, Langmuir monolayers can provide some preliminary insights into the interactions occurring between $\mathrm{CH}$ and $\mathrm{CS}$, which can help in understanding the potential role of subtle modifications of the composition of the meibomian film on the performance of the tear film, giving information on some specific aspects of the relationships between lipid organization and functionality on the meibomian film [50]. Figure $2 \mathrm{a}$ displays the $\Pi-\mathrm{A}_{\mathrm{m}}$ isotherms for selected mixtures of $\mathrm{CH}$ and $\mathrm{CS}$ with different molar fractions of $\mathrm{CH}\left(\mathrm{x}_{\mathrm{CH}}\right)$.

The mutual interaction of $\mathrm{CH}$ and $\mathrm{CS}$ results in a strong synergism between both lipids, leading to isotherms for the mixtures, which correspond to the most compressed states compared to those of the pure components. This can be understood considering the condensing effects of $\mathrm{CH}$ in membranes [51]. Accordingly, the addition of $\mathrm{CH}$ may induce conformational changes in the hydrophobic moieties of the CS, and reduces the hindrance of their packing, taking the orientation of the hydrophobic moieties towards the central axis of the molecule. This decrease in the free volume and cross section of the molecules, and hence the area occupied by the molecules, is strongly reduced with any apparent change on the surface pressure [52-56]. At the highest molar fraction of $\mathrm{CH}$, the condensing effect starts to be reduced, and the isotherms of the mixtures become steeper with a shape resembling that of pure $\mathrm{CH}$. A more detailed analysis of the condensing effect may be extracted from the dependence of the limiting area per molecule of $A_{m}^{\lim }$ on $x_{C H}$ shown in Figure $2 \mathrm{~b}$. This limiting area can be determined from the extrapolation of the maximum slope of the isotherm to $\Pi=0$ [57]. 
a)
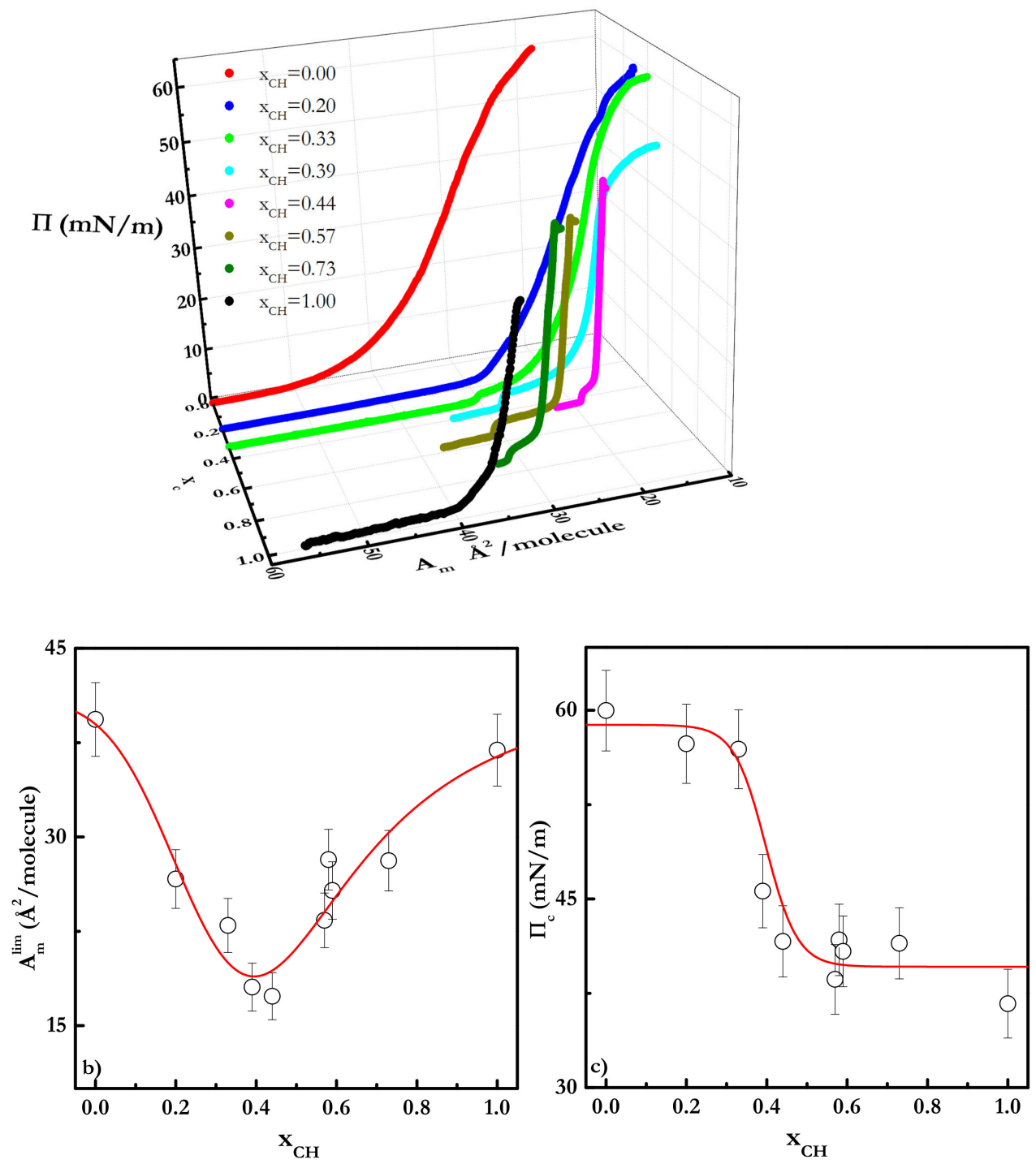

Figure 2. (a) Selected surface pressure-area per molecule isotherms for Langmuir monolayers of mixtures of $\mathrm{CH}$ and $\mathrm{CE}$ with different $\mathrm{x}_{\mathrm{CH}}$ spread at the water/vapor interface at $24{ }^{\circ} \mathrm{C}$. (b) Dependence on the limiting area per molecule on $\mathrm{x}_{\mathrm{CH}}$ for Langmuir monolayers of mixtures of $\mathrm{CH}$ and $\mathrm{CE}$ spread at the water/vapor interface at $24{ }^{\circ} \mathrm{C}$. (c) Dependence of the collapse pressure on $\mathrm{x}_{\mathrm{CH}}$ for Langmuir monolayers of mixtures of $\mathrm{CH}$ and $\mathrm{CE}$ spread at the water/vapor interface at $24{ }^{\circ} \mathrm{C}$. Note that solid lines in panel $(\mathbf{b}, \mathbf{c})$ are guides for the eyes.

The dependence of the limiting area per molecule on the $\mathrm{x}_{\mathrm{CH}}$ points out the condensing effect of the addition of $\mathrm{CH}$ on the behavior of the $\mathrm{CS}$ independently on the $\mathrm{x}_{\mathrm{CH}}$ values. However, this condensing effect is more intense at a well-defined region separated for a threshold value of $x_{C H}$ in the range $0.40-0.50$. For the lowest values of $x_{C H}$, the condensing effect is enhanced with the increase in the molar fraction of $\mathrm{CH}$, whereas for the highest concentrations, this starts to be reduced with the increase in the $\mathrm{CH}$ content on the mixture. This can be understood considering that at a low molar fraction of $\mathrm{CH}$, the lateral packing is enhanced by the ability of cholesterol for condensing the CS molecules at the interface, i.e., low amounts of $\mathrm{CH}$ reduce the steric hindrance to the packing $\mathrm{CS}$ hydrophobic moieties. Therefore, $\mathrm{CH}$ can order the hydrophobic moieties of the CS molecules, which may result in the formation of ordered phases in a disordered liquid-like matrix. Hence, on average, the behavior of the mixed film shifts to more condensed states with respect to the CS monolayers. However, the addition of $\mathrm{CH}$ to the mixture above the threshold value of $\mathrm{x}_{\mathrm{CH}}$ results in the formation of lipid monolayers with a behavior reminiscent to that of $\mathrm{CH}$. This 
can be understood considering that the main component of the mixtures becomes the $\mathrm{CH}$, and hence the $\mathrm{CS}$ appears as insertions within the packed $\mathrm{CH}$ matrix. This indicates that there are regions in the monolayer where the $\mathrm{CH}$ helps the packing of the CS molecules, surrounded for domains of pure $\mathrm{CH}$ [58].

Further details on the interactions occurring within the monolayer as function of the $\mathrm{x}_{\mathrm{CH}}$ are obtained by a thermodynamic analysis $[59,60]$. Thus, for an ideal mixture of lipids at the fluid interface, i.e., non-interacting species, it would be expected that for certain values of the surface pressure, the average area occupied for a molecule may be written as

$$
\mathrm{A}_{\mathrm{m}}^{\mathrm{i}}=\mathrm{x}_{\mathrm{CH}} \mathrm{A}_{\mathrm{m}}^{\mathrm{CH}}+\left(1-\mathrm{x}_{\mathrm{CH}}\right) \mathrm{A}_{\mathrm{m}}^{\mathrm{CS}}
$$

with $\mathrm{A}_{\mathrm{m}}^{\mathrm{CH}}$ and $\mathrm{A}_{\mathrm{m}}^{\mathrm{CS}}$ being the area per molecule at a fixed surface pressure for monolayers of the pure lipids. For monolayers in which the interactions between the lipids play an important role, it is possible to define the average excess area per molecule $A_{m}^{E}$ as

$$
\mathrm{A}_{\mathrm{m}}^{\mathrm{E}}=\mathrm{A}_{\mathrm{m}}^{12}-\mathrm{A}_{\mathrm{m}}^{\mathrm{i}}
$$

where $A_{m}^{12}$ corresponds to the average area per molecule measured directly from the isotherm for a specific mixture as a fixed value of surface pressure. Therefore, considering a specific mixture, it is possible to obtain the values of $A_{m}^{12}, A_{m}^{C H}$ and $A_{m}^{C S}$, at a fixed value of surface pressure, from the corresponding isotherms. Figure 3 a shows the values for $\mathrm{A}_{\mathrm{m}}^{12}$ for the mixed systems at surface pressure of 5, 10, 15, 20, 25, 30 and $35 \mathrm{mN} / \mathrm{m}$.
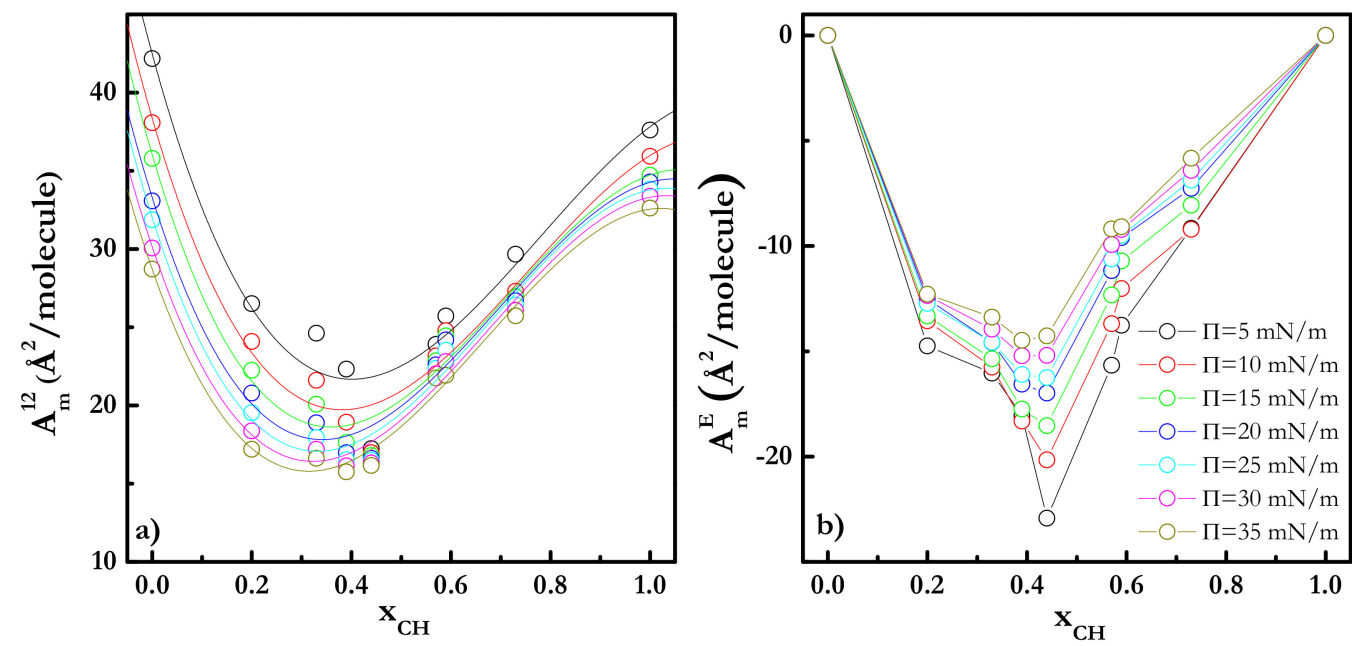

Figure 3. (a) Dependences of the experimental average areas per molecule on $\mathrm{x}_{\mathrm{CH}}$ for binary mixtures of $\mathrm{CH}$ and $\mathrm{CS}$ spread at the water/vapor interface at different surface pressures at $24^{\circ} \mathrm{C}$. (b) Dependence of the average excess area per molecule on $\mathrm{x}_{\mathrm{CH}}$ for Langmuir monolayers of mixtures of $\mathrm{CH}$ and $\mathrm{CE}$ spread the water/vapor interface at different surface pressures at $24^{\circ} \mathrm{C}$. In both panels, the lines are guides for the eyes and the color guide is the same.

For ideal mixtures, or for completely phase-separated mixtures, it would be expected that the lines calculated considering additivity of the components (Equation (6)) should overlap with the experimental $A_{m}^{12}$ values, and the $A_{m}^{E}$ should assume a null value (see Figure $3 b$ ). However, according to the results it is clear the existence of attractive interactions between $\mathrm{CH}$ and $\mathrm{CS}$ within the entire range of monolayer compositions, which is evidenced by the negative values of the $A_{m}^{E}$. This negative deviation confirms the condensing effect of the $\mathrm{CH}$ in the $\mathrm{CS}$ monolayers discussed above.

A more detailed analysis shows that $A_{m}^{E}$ is negative independent of the surface pressure and molar fraction of $\mathrm{CH}$ in the mixture, i.e., the monolayers of the mixtures present a non-ideal behavior, with the maximum condensing effect of $\mathrm{CH}$ appearing in the $\mathrm{x}_{\mathrm{CH}}$ range $0.40-0.50$. The more negative values of $\mathrm{A}_{\mathrm{m}}^{\mathrm{E}}$ indicate that the interactions between $\mathrm{CH}$ and $\mathrm{CS}$ are stronger and a complete mixing of both lipids can be expected. 
Furthermore, the lower the surface pressure, the stronger the condensing effect of the $\mathrm{CH}$ on the monolayer. The above results allow us to suggest that there are two different states for the organization of $\mathrm{CH}$ and $\mathrm{CS}$ at the interface. For $\mathrm{x}_{\mathrm{CH}} \leq 0.50$, it may be expected that the effective area occupied for each $\mathrm{CH}$ molecule is lower than what is reasonable for $\mathrm{CH}$ molecules. Hence, the CS molecules are distributed in such a way that may undergo a significant area shrinkage to ensure the homogeneous distribution of $\mathrm{CH}$ molecules within the monolayer, as was discussed by Miyoshi and Kato for monolayers of different saturated diacylphosphocolines and $\mathrm{CH}$ [60]. For $\mathrm{x}_{\mathrm{CH}} \geq 0.50$, the condensing effect starts to be reduced because the increase in the cholesterol molar fraction counteracts the effect of area shrinkage of CS molecules, which makes possible the formation of domains of pure $\mathrm{CH}$ and the increase of the average area per molecule for the lipids at the interface. Further details on the interaction between the lipids may be obtained from the excess free energy

$$
\Delta \mathrm{G}^{\mathrm{E}}=\mathrm{N}_{\mathrm{Av}} \int_{0}^{\Pi} \mathrm{A}_{\mathrm{m}}^{\mathrm{E}} \mathrm{d} \Pi
$$

with $\mathrm{N}_{\mathrm{Av}}$ being the Avogadro's number. Figure 4 displays the dependence of the excess free energy on the molar fraction of $\mathrm{CH}$ for monolayers of lipid mixtures spread at the water/vapor interface.

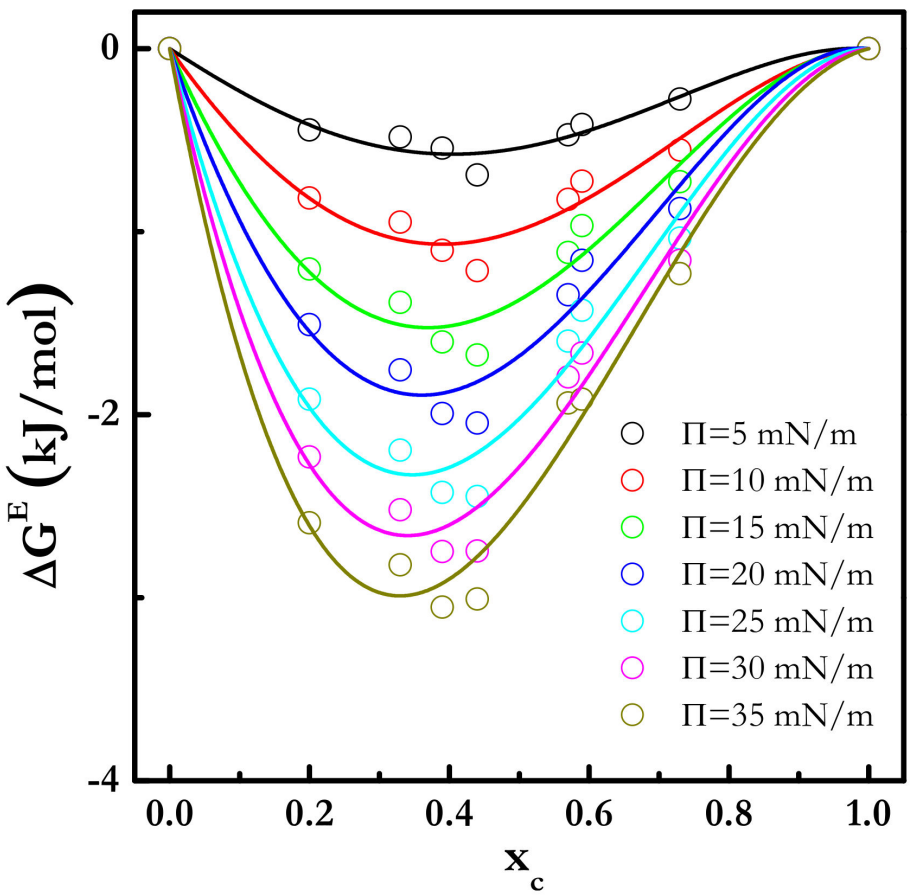

Figure 4. Dependences of the excess free energy of mixing on $\mathrm{x}_{\mathrm{CH}}$ for binary mixtures of $\mathrm{CH}$ and $\mathrm{CS}$ spread at the water/vapor interface at different surface pressures at $24{ }^{\circ} \mathrm{C}$. The lines represent the fitting of the experimental data to a Redlich-Kister type Equation (Equation (9)).

The excess free energy for the mixtures is evidence that the higher the surface pressure, the higher the stability of the mixed system in relation to the monolayers of the pure lipids. This may be interpreted considering an enhanced packing on the mixed monolayers. Furthermore, for monolayers with a molar fraction of $\mathrm{CH}$ in the range $0.40-0.50$, the mixing is significantly enhanced in relation to the pure components, evidencing a transition between two regimes on the stability of the mixed monolayers. This unexpected behavior on mixtures of $\mathrm{CH}$ and $\mathrm{CS}$ may be ascribed to the possible formation of hydrogen bonds between $\mathrm{CH}$ and $\mathrm{CS}$, together with the lateral van der Waals cohesive interactions. This may define the organization of the molecules at the interface, providing additional stability to the monolayer, similar to what was reported for monolayers of $\mathrm{CH}$ and sphingomyelin [51]. 
The excess free energy for the mixture has been approximated using a Redlich-Kistertype equation reading as follows [61]

$$
\Delta \mathrm{G}^{\mathrm{E}}=\mathrm{x}_{\mathrm{CH}} \mathrm{x}_{\mathrm{CS}}\left(\mathrm{A}_{1}+\mathrm{A}_{2}\left(1-2 \mathrm{x}_{\mathrm{CS}}\right)+\mathrm{A}_{3}\left(1-2 \mathrm{x}_{\mathrm{CS}}\right)^{2}\right)
$$

with $A_{1}, A_{2}$ and $A_{3}$ being the coefficients of the model. The best-fit parameters for the excess free energy in terms of Equation (9) are given in Table 1. Even though the model provides the right order of magnitude of the experimental results, it does not provide a good description of the region in which the maximum condensing effect of cholesterol was found, predicting, independently of the surface pressure, smaller values than those obtained from the experimental data.

Table 1. Coefficient obtained for the best fit of the experimental data of the excess free energy for the mixture to Equation (10) at $24^{\circ} \mathrm{C}$.

\begin{tabular}{|c|c|c|c|}
\hline$\Pi(\mathrm{mN} / \mathrm{m})$ & $A_{1}(\mathrm{~kJ} / \mathrm{mol})$ & $\mathrm{A}_{2}(\mathrm{~kJ} / \mathrm{mol})$ & $\mathrm{A}_{3}(\mathrm{~kJ} / \mathrm{mol})$ \\
\hline 5 & -2.17 & 1.35 & 1.06 \\
\hline 10 & -3.97 & 2.65 & 1.24 \\
\hline 15 & -5.49 & 4.38 & 1.35 \\
\hline 20 & -6.72 & 5.75 & 1.39 \\
\hline 25 & -8.09 & 7.37 & 0.70 \\
\hline 30 & -9.14 & 8.53 & 0.16 \\
\hline 35 & -10.06 & 9.91 & -0.81 \\
\hline
\end{tabular}

Further details on the organization of the lipids within the monolayer can be obtained from the quasi-static dilational elasticity displayed in Figure 5.
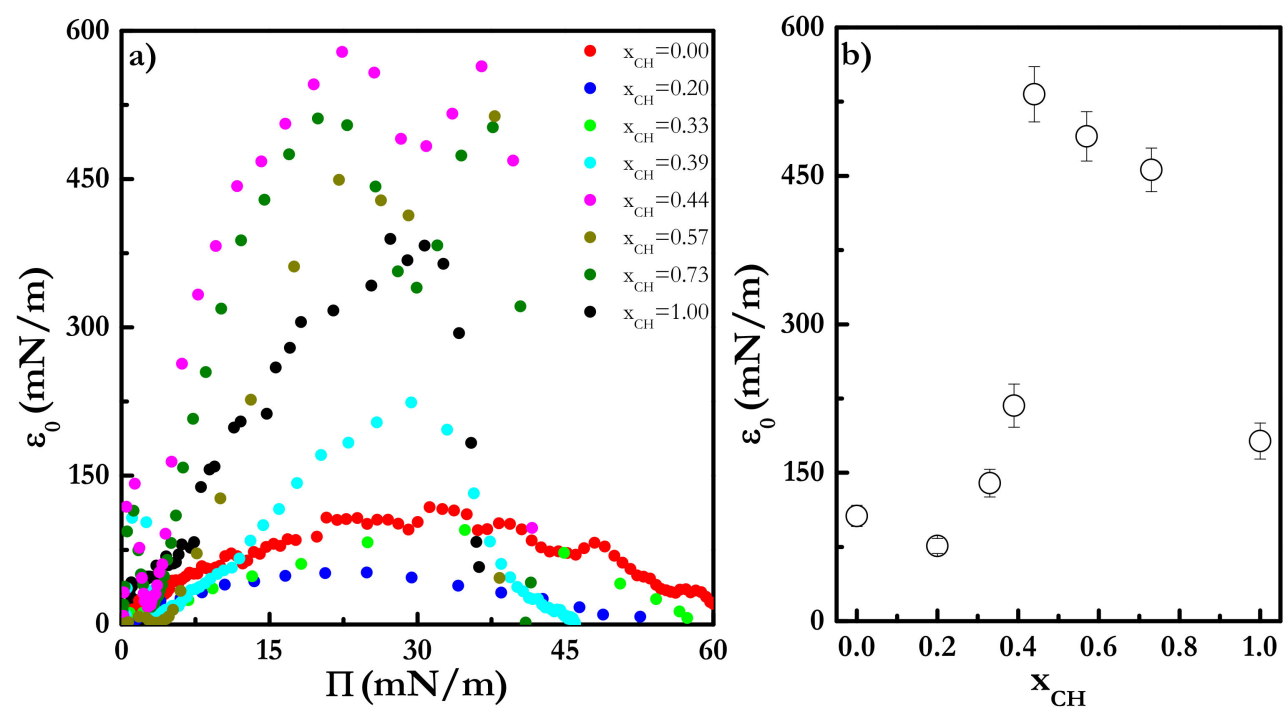

Figure 5. (a) Quasi-static dilational elasticity, $\varepsilon_{0}$, dependences on the surface pressure, $\Pi$, for Langmuir monolayers of mixtures of $\mathrm{CH}$ and $\mathrm{CE}$ spread at the water/vapor interface at $24{ }^{\circ} \mathrm{C}$. (b) Dependence of the quasi-static dilational elasticity, $\varepsilon_{0}$, on the $\mathrm{CH}$ molar fraction, $\mathrm{x}_{\mathrm{CH}}$, at $\Pi=35 \mathrm{mN} / \mathrm{m}$ at $24^{\circ} \mathrm{C}$.

The quasi-static dilational elasticity of the binary mixtures of $\mathrm{CH}$ and $\mathrm{CS}$ presents an anomalous dependence on the molar fraction of $\mathrm{CH}$. For the lowest molar fraction of $\mathrm{CH}$, $\varepsilon_{0}$ drops below the value corresponding to the pure components. Then, $\varepsilon_{0}$ increases till reaching its maximum value for mixtures with $\mathrm{x}_{\mathrm{CH}}$ in the range $0.40-0.50$, and a further increase of the $\mathrm{x}_{\mathrm{CH}}$ decreases again the value of the quasi-static dilational elasticity. This may be rationalized on the basis of the different ordering of the lipids at the interface. At the lowest values of $x_{C H}(<0.25)$, the mixing process results in the formation of a phase with a 
lower order than that found in monolayers of pure CS. This can be understood considering the above-discussed picture in which insertions of $\mathrm{CH}$ triggers the local ordering of the $\mathrm{CS}$ molecules in their surroundings for ensuring a homogeneous distribution of $\mathrm{CH}$ molecules. On the other side, the $\mathrm{CS}$ molecules that are not close to $\mathrm{CH}$ molecules remains in a disordered state, which on average reduces the cohesion of the interface. This can be associated with the formation of interfacial CS-CH complexes within the matrix of CS. The increase in $\mathrm{x}_{\mathrm{CH}}$ leads to a strong increase in the elasticity, which can be explained assuming that the $\mathrm{CH}$ concentration is high enough to lead to a strong condensation of the CS molecules, enhancing its packing. The decrease in the elasticity for $\mathrm{x}_{\mathrm{CH}}>0.50$ is explained considering that $\mathrm{CH}$ is the main component, and hence the behavior starts to be reminiscent to that of pure $\mathrm{CH}$ monolayers due to the emergence of domains of $\mathrm{CH}$ distributed within the monolayer. The curves in Figure $5 \mathrm{a}$ for the binary mixtures shows additional features that are not present in monolayers of the pure lipids. This is related to the higher richness of the phase behavior of the mixture in relation to that of the pure lipids, in agreement with the appearance of a surface pressure plateau in the $\Pi-A_{m}$ isotherm for $\Pi<5 \mathrm{mN} / \mathrm{m}$ (see Figure 2a) separating two one-phase regions. This is clear from a detailed analysis of the quasi-static dilational elasticity curves of the lipid mixtures, in which three different features are observed: (i) at the lowest surface pressures, the elasticity increases until a maximum related to a disordered liquid phase in which a weak lateral packing between the molecules can be expected; (ii) the elasticity drops with the increase of surface pressure down to reach a null value, indicating a coexistence between two liquid phases with different orders (region of the plateau in the surface pressure-area per molecule isotherm), and (iii) the elasticity increases within a liquid ordered phase up to its maximum value, which may be understood in terms of an enhanced lateral packing, and then the elasticity drops as the monolayer approaches the collapse.

The phase coexistence is a result of the mutual interaction between $\mathrm{CH}$ and $\mathrm{CS}$, which is clearer from Figure $6 a$, where the dependence of the surface pressure of the coexistence plateau on $\mathrm{x}_{\mathrm{CH}}$ is displayed. The coexistence between different phases within the plateau region was confirmed independently by the heterogeneous textures observed by Brewster Angle Microscopy. Figure $6 \mathrm{~b}$ shows the image obtained for monolayers with $\mathrm{x}_{\mathrm{CH}}=0.44$. For other $\mathrm{x}_{\mathrm{CH}}$, similar heterogeneous textures were observed by Brewster Angle Microscopy $[48,62,63]$.
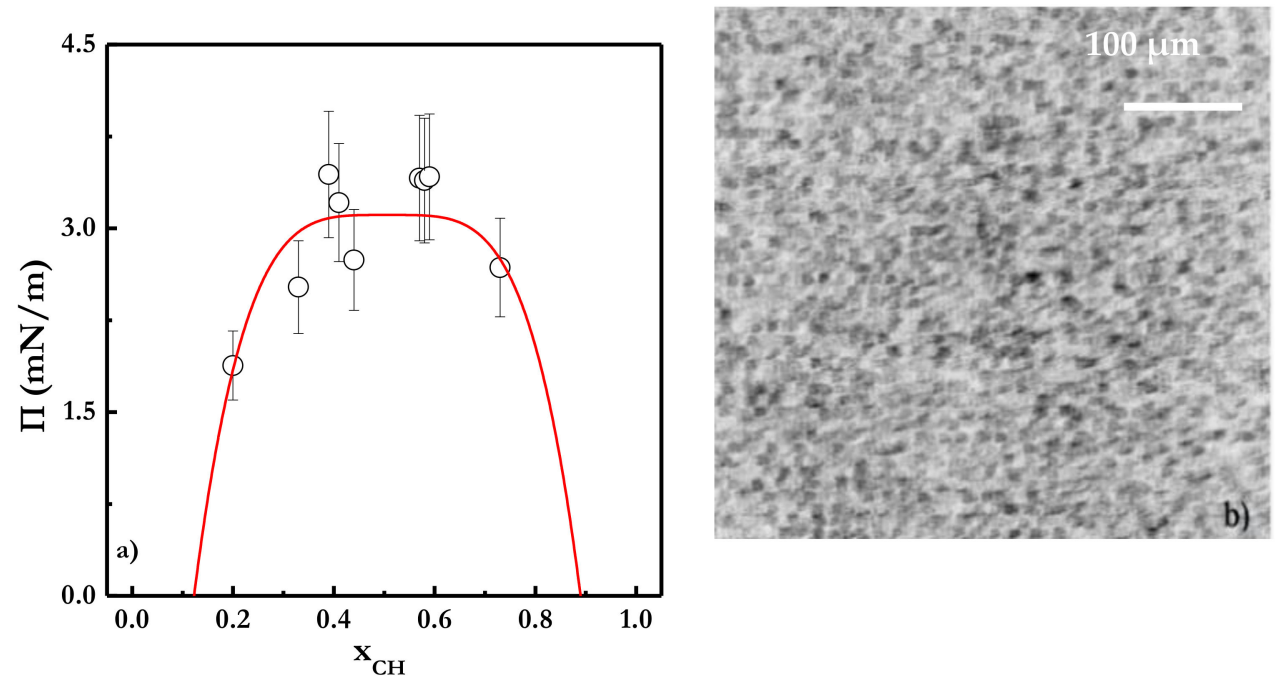

Figure 6. (a) Coexistence surface pressure-cholesterol molar fraction diagram for Langmuir monolayers of mixtures of $\mathrm{CH}$ and CE spread at the water/vapor interface at $24{ }^{\circ} \mathrm{C}$. The symbols are the experimental data and the line represents the theoretical prediction according to Equation (10). (b) Brewster Angle Microscopy image $\left(320 \times 320 \mu \mathrm{m}^{2}\right)$ for the coexistence surface pressure for a Langmuir monolayer of a mixture of $\mathrm{CH}$ and $\mathrm{CE}$ spread at the water/vapor interface with $\mathrm{x}_{\mathrm{CH}}=0.44$ at $24^{\circ} \mathrm{C}$. 
It should be noted that the results of the dependence of the coexistence surface pressure on the cholesterol molar fraction can help to understand the distribution of the two lipids within the interface. According to Hagen and McConnell [64], the dependence of the coexistence on $\mathrm{x}_{\mathrm{CH}}$ can be described in terms of the following relationship:

$$
\mathrm{x}_{\mathrm{CH}}-\mathrm{x}_{\mathrm{CH}}^{\mathrm{c}}=\mathrm{F}\left(\Pi^{\mathrm{c}}-\Pi\right)^{\beta}
$$

with $x_{\mathrm{CH}}^{\mathrm{c}}$ and $\Pi^{\mathrm{c}}$ being the critical composition and surface pressure, respectively. $\beta$ is the so-called critical exponent and F, an adjustable parameter. The application of the model defined for Equation (8) to the experimental results leads to the red curve displayed in Figure $3 a$, with $x_{C H}^{c}$ and $\Pi^{c}$ taking the values $0.51 \pm 0.04$ and $3.1 \pm 0.2$, respectively and $\beta=0.250 \pm 0.005$. The value of $\beta$ suggests that within the phase coexistence, the monolayers of $\mathrm{CH}$ and $\mathrm{CS}$ are in an intermediate state between a 2D system and a $3 \mathrm{D}$ one ( $\beta=0.125$ and 0.39 for $2 \mathrm{D}$ and $3 \mathrm{D}$ systems, respectively $[65,66])$. This picture agrees with the effect of $\mathrm{CH}$ on the monolayers of a broad range of lipids. For the case of $\mathrm{x}_{\mathrm{CH}}^{\mathrm{c}}$ the value obtained is comparable to those reported for the interaction of $\mathrm{CH}$ with different unsaturated lipids, and indicates that $\mathrm{CH}$ and $\mathrm{CS}$ are equivalent in the mixing monolayer [64]. This is compatible with the existence of two different regimes on the condensation of the monolayers as function of the $\mathrm{x}_{\mathrm{CH}}$, and the control of the monolayer packing due to the insertions of the minority compound in the monolayer.

The collapse pressure, $\Pi_{c}$, i.e., the highest surface pressure that the monolayer can reach without rupture or formation of $3 \mathrm{D}$ structure, is more very important information that can be extracted from the surface pressure-area per molecule isotherm. According to the phase rule, the collapse pressure also provides information on the miscibility of the lipids. The existence of a single collapse pressure, which changes as a function of the composition, is an indication of miscibility. On the other side, for immiscible lipids, two different collapse pressures should appear, one belonging to each lipid [67]. For the particular case of binary mixtures of $\mathrm{CH}$ and $\mathrm{CS}$, the existence of single collapse pressure confirms their miscibility in agreement with the strong area contraction discussed above. The collapsed surface pressure value decreases gradually with the increase of the increase of $\mathrm{x}_{\mathrm{CH}}$ (see Figure 2c). This evidences a reduction in the effectiveness in reducing the surface tension, and hence the worsening of the mechanical performance with the incorporation of $\mathrm{CH}$ within the monolayer. This suggests that the composition of the meibomiam secretion plays a central role in the control of its mechanical stability and consequently it may be expected that its physiological performance can be compromised.

\subsection{Equilibrium Behavior of Langmuir Monolayers of Cholesterol-Cholesteryl Estearate Mixtures at $35^{\circ} \mathrm{C}$}

The above discussion has provided important insights into the effect of the composition of the interfacial behavior of model Langmuir monolayers of meibomiam secretion. However, to deepen the understanding of the physico-chemical basis of the effect of composition on the performance of meibum under bio-relevant conditions, it is necessary to explore the behavior of the monolayers at a temperature closer to that found in the eye surface $\left(35^{\circ} \mathrm{C}\right)$ [29]. Figure 7 shows the $\Pi-\mathrm{A}_{\mathrm{m}}$ isotherms for selected mixtures of $\mathrm{CH}$ and $\mathrm{CS}$ with different $\mathrm{x}_{\mathrm{CH}}$ at $35^{\circ} \mathrm{C}$.

The results at $35^{\circ} \mathrm{C}$ are qualitatively similar to those obtained at $24{ }^{\circ} \mathrm{C}$, with the $\mathrm{CH}$ leading to a strong condensing effect, which is reduced as its molar fraction and overcomes a threshold value. This threshold value of the molar fraction of $\mathrm{CH}$ is smaller as the temperature increases, $0.40-0.50$ at $24{ }^{\circ} \mathrm{C}$ vs. $0.20-0.30$ at $35^{\circ} \mathrm{C}$ as evidenced by the minima in the curves of the limit area per molecule (see Figure $2 b$ or Figure $7 b$ ). However, the cholesterol-induced condensing effect is clearly reduced by the increase of the temperature, in agreement with previous studies in the literature $[68,69]$. The decrease in the collapse surface pressure also appears qualitatively similar for the two explored temperatures (see Figure 2c or Figure 7c). 
a)
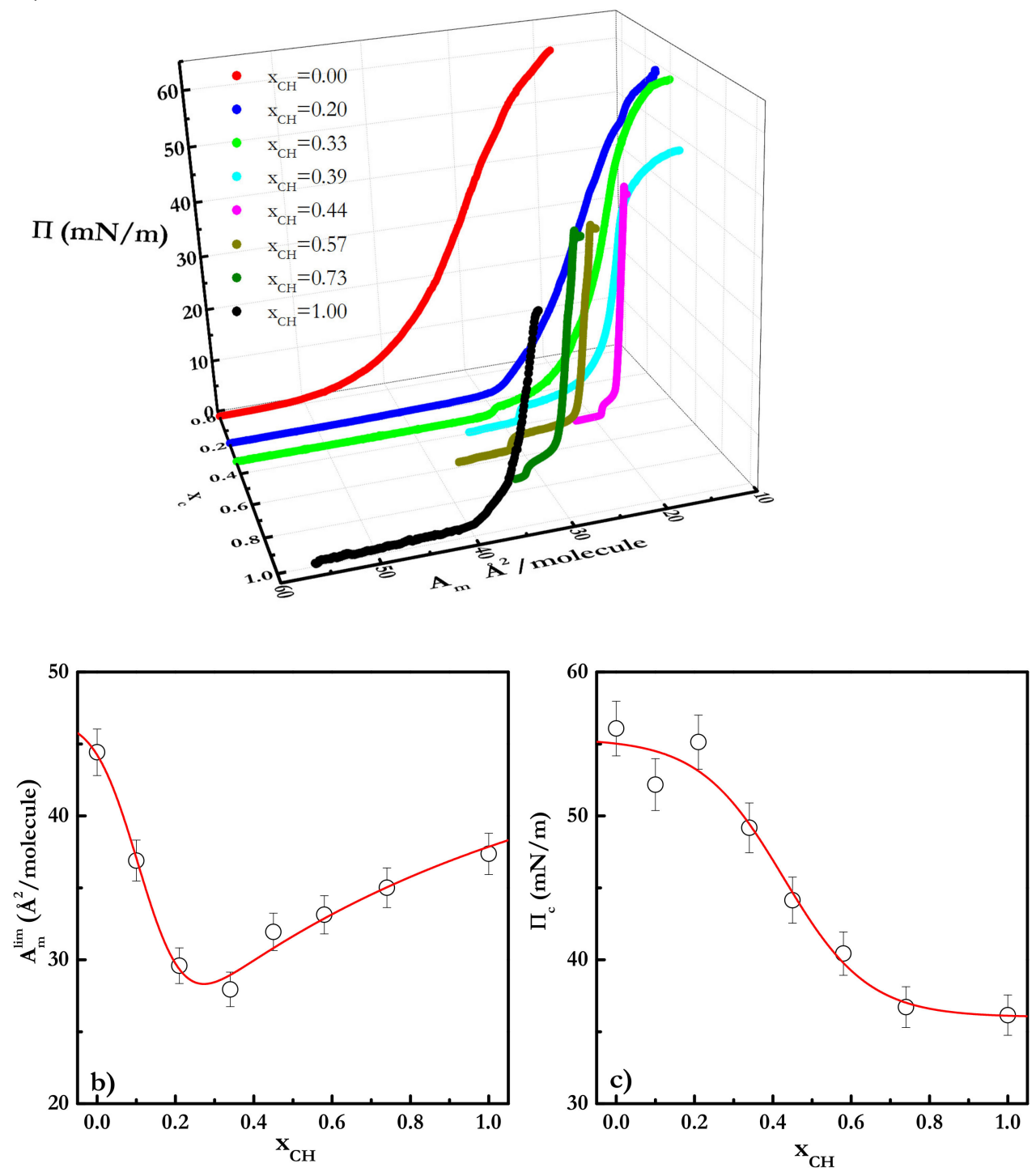

Figure 7. (a) Selected surface pressure-area per molecule isotherms for Langmuir monolayers of mixtures of $\mathrm{CH}$ and $\mathrm{CE}$ with different $\mathrm{x}_{\mathrm{CH}}$ spread at the water/vapor interface at $35^{\circ} \mathrm{C}$. (b) Dependence of the limiting area per molecule on $\mathrm{x}_{\mathrm{CH}}$ for Langmuir monolayers of mixtures of $\mathrm{CH}$ and $\mathrm{CE}$ spread at the water/vapor interface at $35^{\circ} \mathrm{C}$. (c) Dependence of the collapse pressure on $\mathrm{x}_{\mathrm{CH}}$ for Langmuir monolayers of mixtures of $\mathrm{CH}$ and $\mathrm{CE}$ spread at the water/vapor interface at $35^{\circ} \mathrm{C}$. The solid lines in panel $(\mathbf{b}, \mathbf{c})$ are guides for the eyes.

The main difference in the phase behavior together with the region in which the cholesterol-induced condensing effect is maximum, is the disappearance of the phase coexistence region at $35^{\circ} \mathrm{C}$, i.e, the surface pressure plateau (see Figure 2a). This and the reduction of the condensing effect of the $\mathrm{CH}$ may be understood considering that when increasing the temperature of the fluidity of the lipid monolayer increases [70]. This is clear by observing the quasi-static dilational values of the lipid monolayers at $35^{\circ} \mathrm{C}$ reported in Figure 8 . The increase in the temperature leads to a decrease in the average elasticity of the lipid monolayers. Furthermore, from the elasticity curves, it is clear that the mixtures of $\mathrm{CH}$ and $\mathrm{CS}$ presents the typical behavior of a fluid film, showing only a maximum in the quasi-static dilational elasticity curve. 

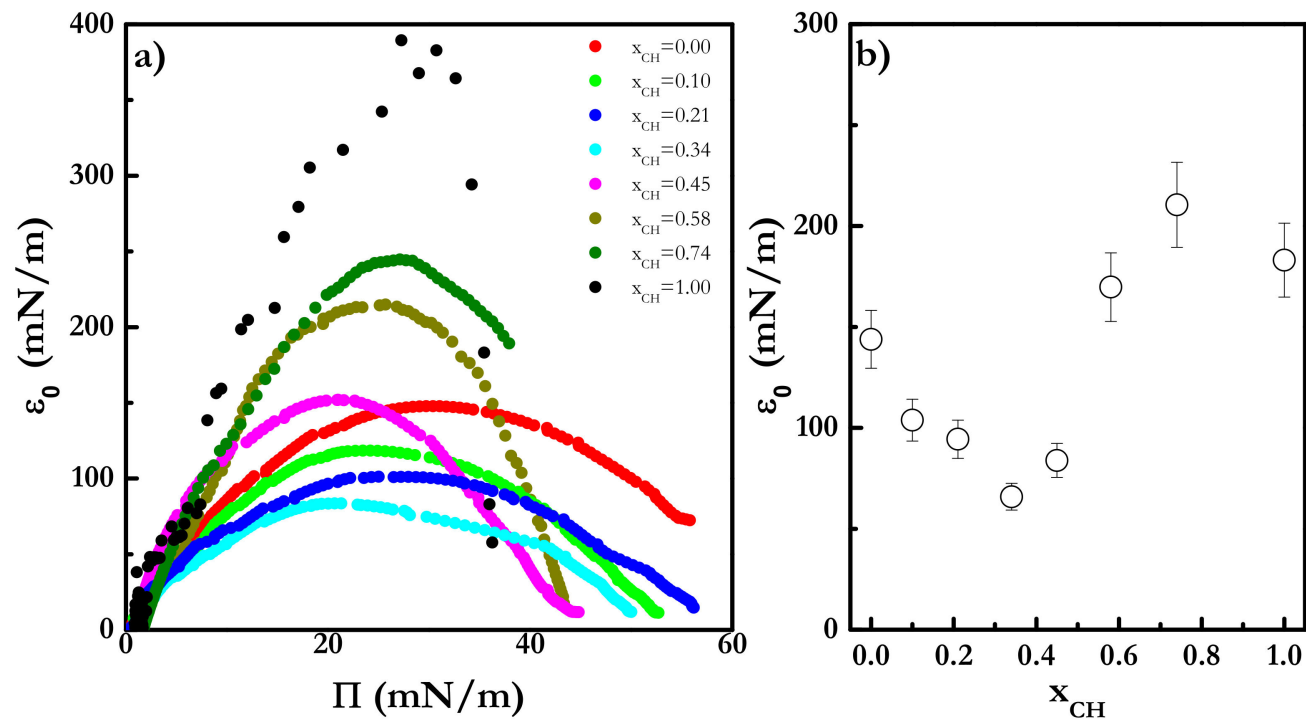

Figure 8. (a) Quasi-static dilational elasticity, $\varepsilon_{0}$, dependences on the surface pressure, $\Pi$, for Langmuir monolayers of mixtures of $\mathrm{CH}$ and $\mathrm{CE}$ spread at the water/vapor interface at $35^{\circ} \mathrm{C}$. (b) Dependence of the quasi-static dilational elasticity, $\varepsilon_{0}$, on the $\mathrm{CH}$ molar fraction, $\mathrm{x}_{\mathrm{CH}}$, at $\Pi=35 \mathrm{mN} / \mathrm{m}$ at $35^{\circ} \mathrm{C}$.

Figure $8 \mathrm{~b}$ illustrates the dependence of the quasi-static dilational elasticity on the cholesterol molar fraction at $35 \mathrm{mN} / \mathrm{m}$. The results agree qualitatively with those found at the lowest studied temperature, and again the smaller condensing effect of the cholesterol confirms the fluid-like character of the lipid layer with the increase of the temperature.

The results of the thermodynamic analysis for the area contraction at $35^{\circ} \mathrm{C}$, shown in Figure 9, follows similar trends to those reported above for monolayers at $24^{\circ} \mathrm{C}$, confirming also in this case the existence of different types of organizations for the molecules at the interface.
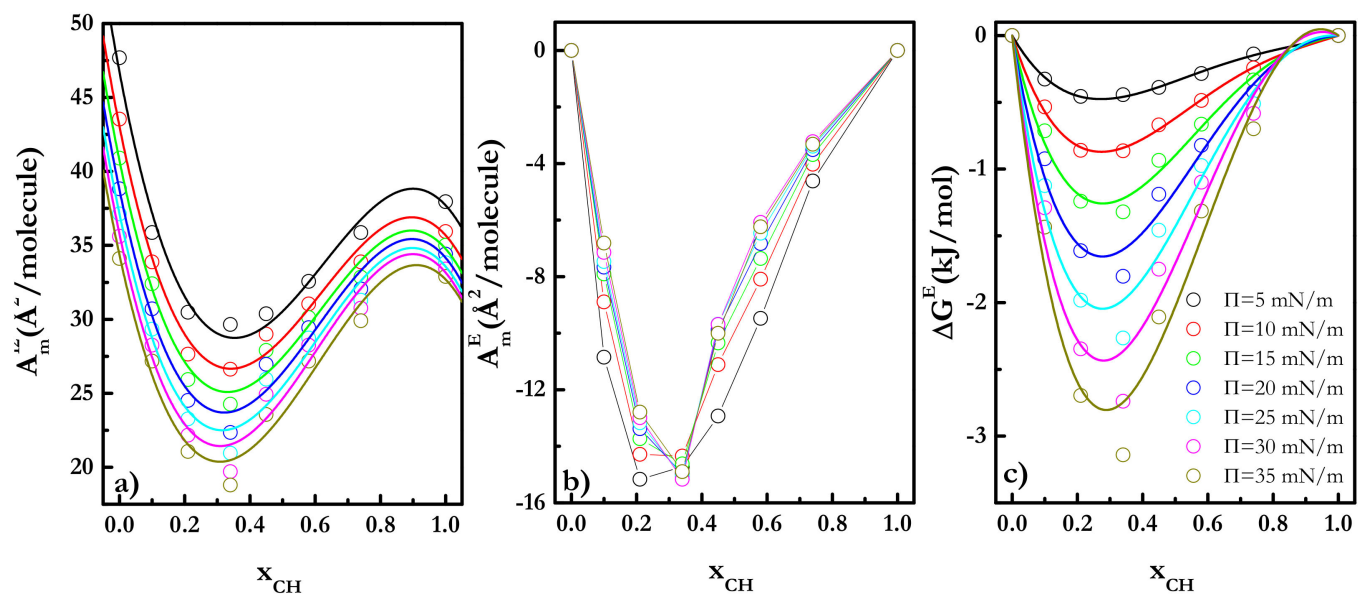

Figure 9. (a) Dependences of the experimental average areas per molecule on $\mathrm{x}_{\mathrm{CH}}$ for binary mixtures of $\mathrm{CH}$ and $\mathrm{CS}$ spread at the water/vapor interface at different surface pressures at $35^{\circ} \mathrm{C}$. The lines are guides for the eyes. (b) Dependence of the average excess area per molecule on $\mathrm{x}_{\mathrm{CH}}$ for Langmuir monolayers of mixtures of $\mathrm{CH}$ and $\mathrm{CE}$ spread at the water/vapor interface at different surface pressures at $35^{\circ} \mathrm{C}$. The lines are guides for the eyes. (c) Dependences of the excess free energy of mixing on $\mathrm{x}_{\mathrm{CH}}$ for binary mixtures of $\mathrm{CH}$ and $\mathrm{CS}$ spread at the water/vapor interface at different surface pressures at $35{ }^{\circ} \mathrm{C}$. The lines represent the fitting of the experimental data to a Redlich-Kister-type equation (Equation (9)). The color legend is the same for the three panels.

The contraction of area appears smaller at $35{ }^{\circ} \mathrm{C}$ than at $24{ }^{\circ} \mathrm{C}$, which confirms the smaller condensing effect of the $\mathrm{CH}$ associated with the more fluid character of the mixed 
monolayers. On the other side, the information obtained from the curves of $\Delta G^{\mathrm{E}}$ is qualitatively in agreement with that obtained at the lowest studied temperature. However, at $35^{\circ} \mathrm{C}$, the disagreement between the excess free energy derived from the experimental data and the prediction obtained using a Redlich-Kister-type equation is stronger than at $24^{\circ}$. Table 2 reports the best-fit parameters for the excess free energy in terms of Equation (9) at $35^{\circ} \mathrm{C}$.

Table 2. Coefficient obtained for the best fit of the experimental data of the excess free energy for the mixture to Equation (10) at $35^{\circ} \mathrm{C}$.

\begin{tabular}{|c|c|c|c|}
\hline$\Pi(\mathrm{mN} / \mathrm{m})$ & $A_{1}(\mathrm{~kJ} / \mathrm{mol})$ & $A_{2}(\mathrm{~kJ} / \mathrm{mol})$ & $\mathrm{A}_{3}(\mathrm{~kJ} / \mathrm{mol})$ \\
\hline 5 & -1.37 & 1.77 & -1.09 \\
\hline 10 & -2.48 & 3.42 & -1.74 \\
\hline 15 & -3.59 & 5.15 & -1.99 \\
\hline 20 & -4.66 & 6.98 & -2.50 \\
\hline 25 & -5.72 & 8.78 & -2.91 \\
\hline 30 & -6.83 & 10.71 & -2.78 \\
\hline 35 & -8.12 & 12.15 & -2.23 \\
\hline
\end{tabular}

\subsection{Response of Langmuir Monolayers of Cholesterol-Cholesteryl Estearate Mixtures upon Dilational Stresses}

It was mentioned above that lipids are subjected to mechanical perturbations in the tear fluid. Therefore, the characterization of the response of these lipids under periodic perturbation appears as an essential point for trying to shed light on the role of the composition on the mechanical performance of meibum. Figure 10 shows the values of the dilational elasticity $\varepsilon$ l and dilational viscous modulus, $\varepsilon^{\prime \prime}=2 \pi v \kappa$, for monolayers of $\mathrm{CH}$ and CS of different compositions obtained by the oscillatory barrier method at a perturbation frequency of $0.1 \mathrm{~Hz}$, which is compatible with the average blinking frequency in healthy individuals [28]. Thus, the viscoelastic parameters were obtained upon the application of a periodic sinusoidal deformation of the interfacial area available for the lipid monolayer at a reference surface pressure value, followed by the analysis of the surface pressure response by combining Equations (1)-(4).
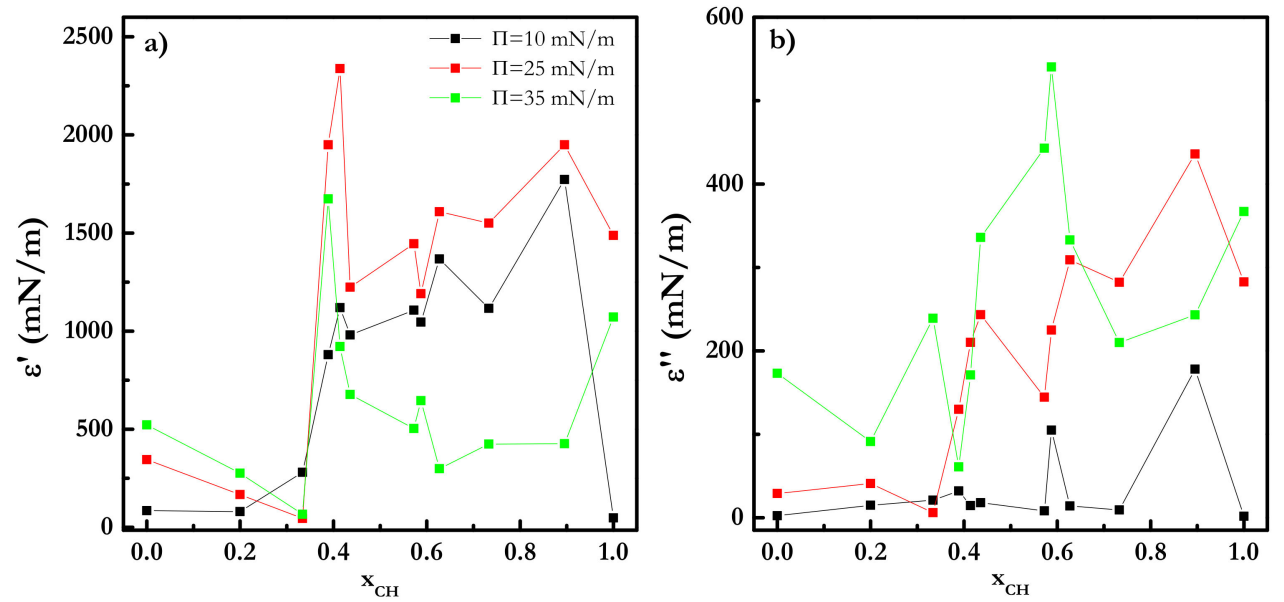

Figure 10. (a) Dependences of the dilational elasticity on $\mathrm{x}_{\mathrm{CH}}$ for binary mixtures of $\mathrm{CH}$ and CS spread at the water/vapor interface at different surface pressures at $24{ }^{\circ} \mathrm{C}$. (b) Dependences of the dilational viscous modulus on $\mathrm{x}_{\mathrm{CH}}$ for binary mixtures of $\mathrm{CH}$ and $\mathrm{CS}$ spread at the water/vapor interface at different surface pressures at $24^{\circ} \mathrm{C}$. The lines are guides for the eyes, and the color legend is the same for the both panels.

The first point that should be noted according to the obtained values are the large values of the dilational elasticity, independent of the composition of the lipid mixtures. Furthermore, it is evident that a very sharp transition over a very narrow range of cholesterol 
concentrations, which agrees with the change of the organization of the lipid molecules at the fluid interface, i.e., the transition point exhibited by $\varepsilon$, occurs at the composition at which the synergistic effect is maximal in the equilibrium results. It should be mentioned that the mole fraction of cholesterol corresponding to that point is close to the value found in various systems of biological interest: cell membranes, pulmonary surfactants, and tears $[25,71,72]$. Furthermore, the viscous modulus present also has a very high value, and even higher is the dilational viscosity $\mathrm{k}=\varepsilon^{\prime \prime} / 2 \pi v$.

The study of the rheological behavior of monolayers of mixtures of $\mathrm{CH}$ and $\mathrm{CS}$ has also been performed at a physiologically relevant temperature $\left(35^{\circ} \mathrm{C}\right)$. Figure 11 shows the values of the dilational elasticity as a function of the molar fraction of cholesterol for experiments performed at two different deformation frequencies around three different values of the reference pressure.

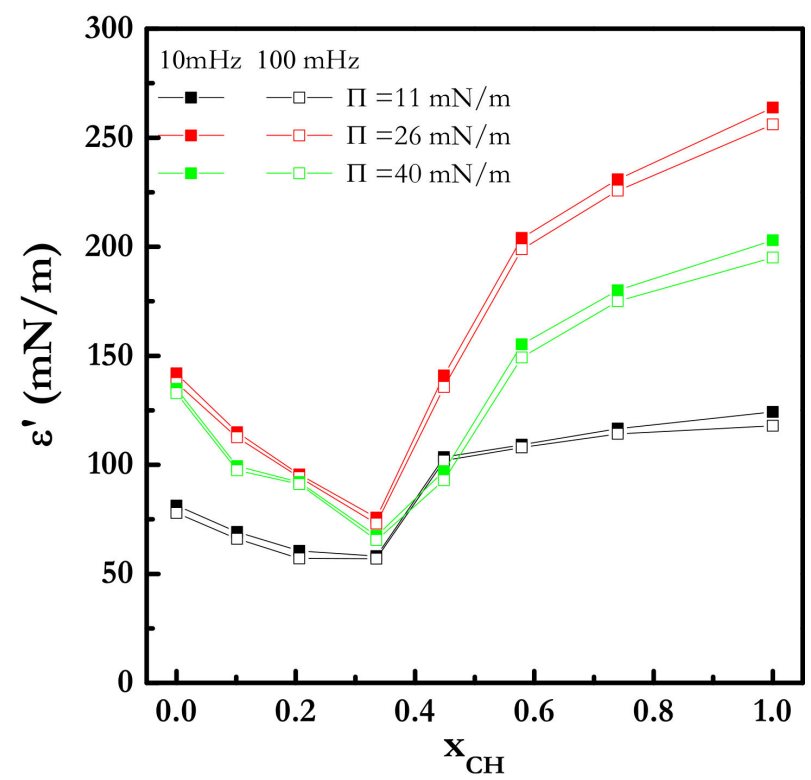

Figure 11. Dependences of the elastic modulus component on $\mathrm{x}_{\mathrm{CH}}$ for binary mixtures of $\mathrm{CH}$ and CS spread at the water/vapor interface at different surface pressures at $35^{\circ} \mathrm{C}$.

The results in Figure 11 point out that the elastic modulus is almost unaffected by the deformation frequency, and that, as expected, the formation of more fluid monolayers results in a significant decrease in the dilational elasticity. However, the observed values remain relatively large, especially in highly packed monolayers with a high $\mathrm{CH}$ content.

\section{Conclusions}

The equilibrium behavior and the response against controlled dilational stresses of Langmuir monolayers formed for mixtures of cholesterol and cholesteryl stearate have been studied as function of the temperature at $24{ }^{\circ} \mathrm{C}$ and $35^{\circ} \mathrm{C}$, aiming at an understanding of the potential effects of the composition on the physico-chemical properties of the biologically relevant model Langmuir monolayers. The analysis of the surface-pressure-area per molecule isotherms has evidenced the existence of a strong synergism between cholesterol and cholesteryl stearate, such synergism being the maximum for specific compositions, which depends on the temperature. The results show that the distribution of the molecules within the interface and their packing are governed by the combination of the condensing effect of cholesterol and the specific composition of the lipid mixtures, with the latter aspect being strongly enhanced by the addition of cholesterol, as evidenced by the high values of the quasi-static elastic modulus. The increase in the rigidity of the monolayers, as cholesterol is added, is also evidenced from the high values of the dynamic viscoelastic modulus obtained from the analysis of the response of the monolayers against dilational 
deformations. Furthermore, it was found that an enhanced interaction between the components of the monolayers defines a sharp transition in the dilational elasticity, which is ascribed to the enhanced lateral interactions between the lipids at the interface.

It should be noted that even the model is rather simple, and the here-obtained results have evidenced that slight modifications of the composition of the Langmuir monolayers may induce strong changes on its properties, which in turn may induce physiological dysfunction of meibum film. This work has been focused on analyzing the behavior of mixtures of two lipids trying to understand the effect of the composition on their interfacial properties. However, the results leave open many questions that should be solved in the future. Firstly, it is necessary to define the best composition for mimicking the specific biological characteristics of the meibum layers, which are relatively complex from the chemical and structural perspective. Furthermore, it is not clear whether oscillatory dilational deformations can be the best representation of the stresses occurring during the physiological processes involved during blinking. For monolayer formulations mimicking the meibum layer, it would also be useful to investigate the response to dilational deformations of both the linear and non-linear regimes. Furthermore, it would be very important to analyze the response of the model film upon shear stresses, because they may contribute significantly to the deformation of the meibum layer during its physiological performance.

Author Contributions: Conceptualization, R.G.R.; methodology, R.G.R.; software, R.G.R. and E.G.; validation, R.G.R.; formal analysis, R.G.R. and E.G.; investigation, R.G.R., E.G., F.O. and L.L.; resources, R.G.R.; data curation, R.G.R.; writing-Original draft preparation, E.G. and R.G.R.; writingReview and editing, R.G.R., E.G., F.O. and L.L.; visualization, E.G.; supervision, R.G.R.; project administration, R.G.R., E.G. and F.O., funding acquisition, R.G.R., E.G., F.O. and L.L. All authors have read and agreed to the published version of the manuscript.

Funding: This work was funded by MICINN under grant PID2019-106557GB-C21, by Banco Santander-Universidad Complutense grant PR87/19-22513 (Spain) and by E.U. on the framework of the European Innovative Training Network-Marie Sklodowska-Curie Action nanoPaInt (grant agreement 955612).

Institutional Review Board Statement: Not applicable.

Informed Consent Statement: Not applicable.

Data Availability Statement: Data are available upon request.

Acknowledgments: Centro de Espectroscopía y Correlación of the Universidad Complutense de Madrid is acknowledge for the use of their facilities. Authors want to thank toTatyana S. Svitova for her critical reading of the manuscript.

Conflicts of Interest: The authors declare no conflict of interest. The funders had no role in the design of the study; in the collection, analyses, or interpretation of data; in the writing of the manuscript, or in the decision to publish the results.

\section{References}

1. Lam, S.M.; Tong, L.; Duan, X.; Petznick, A.; Wenk, M.R.; Shui, G. Extensive characterization of human tear fluid collected using different techniques unravels the presence of novel lipid amphiphiles. J. Lipid Res. 2014, 55, 289-298. [CrossRef] [PubMed]

2. Borchman, D. Lipid conformational order and the etiology of cataract and dry eye. J. Lipid Res. 2021, 62, 100039. [CrossRef] [PubMed]

3. Butovich, I.A. Meibomian glands, meibum, and meibogenesis. Exp. Eye Res. 2017, 163, 2-16. [CrossRef]

4. Yokoi, N.; Bron, A.J.; Georgiev, G.A. The Precorneal Tear Film as a Fluid Shell: The Effect of Blinking and Saccades on Tear Film Distribution and Dynamics. Ocul. Surf. 2014, 12, 252-266. [CrossRef]

5. Berger, R.E.; Corrsin, S. A surface tension gradient mechanism for driving the pre-corneal tear film after a blink. J. Biomech. 1974, 7, 225-238. [CrossRef]

6. Georgiev, G.A.; Eftimov, P.; Yokoi, N. Structure-function relationship of tear film lipid layer: A contemporary perspective. Exp. Eye Res. 2017, 163, 17-28. [CrossRef]

7. Murube, J. The Origin of Tears. III. The Lipid Component in the XIX and XX Centuries. Ocul. Surf. 2012, 10, $200-209$. [CrossRef] [PubMed]

8. Craig, J.P.; Tomlinson, A. Importance of the lipid layer in human tear film stability and evaporation. Optom. Vis. Sci. 1997, 74, 8-13. [CrossRef] [PubMed] 
9. Bron, A.J.; Tiffany, J.M.; Gouveia, S.M.; Yokoi, N.; Voon, L.W. Functional aspects of the tear film lipid layer. Exp. Eye Res. 2004, 78, 347-360. [CrossRef] [PubMed]

10. Butovich, I.A. Tear film lipids. Exp. Eye Res. 2013, 117, 4-27. [CrossRef] [PubMed]

11. McCulley, J.P.; Shine, W. A compositional based model for the tear film lipid layer. Trans. Am. Ophthalmol. Soc. 1997, 95, 79-88, discussion 88-93. [PubMed]

12. Borchman, D.; Foulks, G.N.; Yappert, M.C.; Bell, J.; Wells, E.; Neravetla, S.; Greenstone, V. Human Meibum Lipid Conformation and Thermodynamic Changes with Meibomian-Gland Dysfunction. Invest. Ophthalmol. Vis. Sci. 2011, 52, $3805-3817$. [CrossRef] [PubMed]

13. Faheem, S.; Kim, S.-H.; Nguyen, J.; Neravetla, S.; Ball, M.; Foulks, G.N.; Yappert, M.C.; Borchman, D. Wax-tear and meibum protein, wax- $\beta$-carotene interactions in vitro using infrared spectroscopy. Exp. Eye Res. 2012, 100, 32-39. [CrossRef] [PubMed]

14. Bland, H.C.; Moilanen, J.A.; Ekholm, F.S.; Paananen, R.O. Investigating the Role of Specific Tear Film Lipids Connected to Dry Eye Syndrome: A Study on O-Acyl-w-hydroxy Fatty Acids and Diesters. Langmuir ACS J. Surf. Colloids 2019, 35, 3545-3552. [CrossRef]

15. Souza, S.L.; Hallock, K.J.; Funari, S.S.; Vaz, W.L.C.; Hamilton, J.A.; Melo, E. Study of the miscibility of cholesteryl oleate in a matrix of ceramide, cholesterol and fatty acid. Chem. Phys. Lipids 2011, 164, 664-671. [CrossRef] [PubMed]

16. Georgiev, G.A.; Borchman, D.; Eftimov, P.; Yokoi, N. Lipid Saturation and the Rheology of Human Tear Lipids. Int. J. Mol. Sci. 2019, 20, 3431. [CrossRef] [PubMed]

17. Clayton, J.A. Dry Eye. N. Engl. J. Med. 2018, 378, 2212-2223. [CrossRef] [PubMed]

18. Gayton, J.L. Etiology, prevalence, and treatment of dry eye disease. Clin. Ophthalmol. 2009, 3, 405-412. [CrossRef]

19. Chachaj-Brekiesz, A.; Wnętrzak, A.; Lipiec, E.; Kobierski, J.; Dynarowicz-Latka, P. Perfluorohexyloctane (F6H8) as a delivery agent for cyclosporine A in dry eye syndrome therapy-Langmuir monolayer study complemented with infrared nanospectroscopy. Colloids Surf. B 2019, 184, 110564. [CrossRef] [PubMed]

20. Borchman, D.; Ramasubramanian, A.; Foulks, G.N. Human Meibum Cholesteryl and Wax Ester Variability With Age, Sex, and Meibomian Gland Dysfunction. Invest. Ophthalmol. Vis. Sci. 2019, 60, 2286-2293. [CrossRef] [PubMed]

21. Shrestha, R.K.; Borchman, D.; Foulks, G.N.; Yappert, M.C.; Milliner, S.E. Analysis of the Composition of Lipid in Human Meibum from Normal Infants, Children, Adolescents, Adults, and Adults with Meibomian Gland Dysfunction Using 1H-NMR Spectroscopy. Invest. Ophthalmol. Vis. Sci. 2011, 52, 7350-7358. [CrossRef] [PubMed]

22. King-Smith, P.E.; Hinel, E.A.; Nichols, J.J. Application of a novel interferometric method to investigate the relation between lipid layer thickness and tear film thinning. Invest. Ophthalmol. Vis. Sci. 2010, 51, 2418-2423. [CrossRef] [PubMed]

23. Zhang, Y.L.; Matar, O.K.; Craster, R.V. Analysis of tear film rupture: Effect of non-Newtonian rheology. J. Colloid Interface Sci. 2003, 262, 130-148. [CrossRef]

24. Lemp, M.A.; Crews, L.A.; Bron, A.J.; Foulks, G.N.; Sullivan, B.D. Distribution of aqueous-deficient and evaporative dry eye in a clinic-based patient cohort: A retrospective study. Cornea 2012, 31, 472-478. [CrossRef] [PubMed]

25. Cwiklik, L. Tear film lipid layer: A molecular level view. Biochim. Biophys. Acta-Biomembranes 2016, 1858, 2421-2430. [CrossRef]

26. Lam, S.M.; Tong, L.; Yong, S.S.; Li, B.; Chaurasia, S.S.; Shui, G.; Wenk, M.R. Meibum lipid composition in Asians with dry eye disease. PLoS ONE 2011, 6, e24339. [CrossRef] [PubMed]

27. Birdi, K.S. Lipid and Biopolymer Monolayers at Liquid Interfaces; Plenum Press: New York, NY, USA, 1989.

28. Doughty, M.J. Further Assessment of Gender- and Blink Pattern-Related Differences in the Spontaneous Eyeblink Activity in Primary Gaze in Young Adult Humans. Optom. Vis. Sci. 2002, 79, 439-447. [CrossRef] [PubMed]

29. Purslow, C.; Wolffsohn, J.S. Ocular surface temperature: A review. Eye Contact Lens 2005, 31, 117-123. [CrossRef] [PubMed]

30. Hifeda, Y.F.; Rayfield, G.W. Evidence for first-order phase transitions in lipid and fatty acid monolayers. Langmuir ACS J. Surf. Colloids 1992, 8, 197-200. [CrossRef]

31. Monroy, F.; Ortega, F.; Rubio, R.G. Dilatational rheology of insoluble polymer monolayers: Poly(vinylacetate). Phys. Rev. E 1998, 58, 7629-7641. [CrossRef]

32. Guzmán, E.; Liggieri, L.; Santini, E.; Ferrari, M.; Ravera, F. Influence of silica nanoparticles on dilational rheology of DPPCpalmitic acid Langmuir monolayers. Soft Matter 2012, 8, 3938-3948. [CrossRef]

33. Liggieri, L.; Santini, E.; Guzmán, E.; Maestro, A.; Ravera, F. Wide-frequency dilational rheology investigation of mixed silica nanoparticle-CTAB interfacial layers. Soft Matter 2011, 7, 7699-7709. [CrossRef]

34. Mendoza, A.J.; Guzmán, E.; Martínez-Pedrero, F.; Ritacco, H.; Rubio, R.G.; Ortega, F.; Starov, V.M.; Miller, R. Particle laden fluid interfaces: Dynamics and interfacial rheology. Adv. Colloid Interface Sci. 2014, 206, 303-319. [CrossRef] [PubMed]

35. Monroy, F.; Ortega, F.; Rubio, R.G.; Velarde, M.G. Surface rheology, equilibrium and dynamic features at interfaces, with emphasis on efficient tools for probing polymer dynamics at interfaces. Adv. Colloid Interface Sci. 2007, 134-135, 175-189. [CrossRef] [PubMed]

36. Llamas, S.; Guzman, E.; Akanno, A.; Fernandez-Pena, L.; Ortega, F.; Campbell, R.A.; Miller, R.; Rubio, R.G. Study of the Liquid/Vapor Interfacial Properties of Concentrated Polyelectrolyte-Surfactant Mixtures Using Surface Tensiometry and Neutron Reflectometry: Equilibrium, Adsorption Kinetics, and Dilational Rheology. J. Phys. Chem. C 2018, 122, 4419-4427. [CrossRef]

37. Smaby, J.M.; Brockman, H.L. Novel surface phase containing cholesteryl esters. 2. Nonequivalence of cholesteryl arachidonate and those with 18-carbon, cis-unsaturated acyl groups. Biochemistry 1981, 20, 724-730. [CrossRef] [PubMed]

38. Kwong, C.N.; Heikkila, R.E.; Cornwell, D.G. Properties of cholesteryl esters in pure and mixed monolayers. J. Lipid Res. 1971, 12, 31-35. [CrossRef] 
39. Worthman, L.A.D.; Nag, K.; Davis, P.J.; Keough, K.M.W. Cholesterol in condensed and fluid phosphatidylcholine monolayers studied by epifluorescence microscopy. Biophys. J. 1997, 72, 2569-2580. [CrossRef]

40. Guzmán, E.; Liggieri, L.; Santini, E.; Ferrari, M.; Ravera, F. Mixed DPPC-cholesterol Langmuir monolayers in presence of hydrophilic silica nanoparticles. Colloids Surf. B 2013, 105, 284-293. [CrossRef]

41. Guzmán, E.; Ferrari, M.; Santini, E.; Liggieri, L.; Ravera, F. Effect of silica nanoparticles on the interfacial properties of a canonical lipid mixture. Colloids Surf. B 2015, 136, 971-980. [CrossRef]

42. Przykaza, K.; Woźniak, K.; Jurak, M.; Wiącek, A.E.; Mroczka, R. Properties of the Langmuir and Langmuir-Blodgett monolayers of cholesterol-cyclosporine A on water and polymer support. Adsorption 2019, 25, 923-936. [CrossRef]

43. Reuter, S.; Hofmann, A.M.; Busse, K.; Frey, H.; Kressler, J. Langmuir and Langmuir-Blodgett Films of Multifunctional, Amphiphilic Polyethers with Cholesterol Moieties. Langmuir 2011, 27, 1978-1989. [CrossRef] [PubMed]

44. Lucero, A.; Rodríguez Niño, M.R.; Gunning, A.P.; Morris, V.J.; Wilde, P.J.; Rodríguez Patino, J.M. Effect of Hydrocarbon Chain and $\mathrm{pH}$ on Structural and Topographical Characteristics of Phospholipid Monolayers. J. Phys. Chem. B 2008, 112, 7651-7661. [CrossRef] [PubMed]

45. Guzmán, E.; Liggieri, L.; Santini, E.; Ferrari, M.; Ravera, F. DPPC-DOPC Langmuir monolayers modified by hydrophilic silica nanoparticles: Phase behaviour, structure and rheology. Colloids Surf. A 2012, 413, 174-183. [CrossRef]

46. Davies, J.T.; Rideal, E.K. Interfacial Phenomena; Academic Press: Cambridge, MA, USA, 1963.

47. López-Montero, I.; Arriaga, L.R.; Rivas, G.; Vélez, M.; Monroy, F. Lipid domains and mechanical plasticity of Escherichia coli lipid monolayers. Chem. Phys. Lipids 2010, 163, 56-63. [CrossRef]

48. Guzman, E.; Santini, E.; Zabiegaj, D.; Ferrari, M.; Liggieri, L.; Ravera, F. Interaction of Carbon Black Particles and Dipalmitoylphosphatidylcholine at the Water/Air Interface: Thermodynamics and Rheology. J. Phys. Chem. C 2015, 119, 26937-26947. [CrossRef]

49. King-Smith, P.E.; Bailey, M.D.; Braun, R.J. Four characteristics and a model of an effective tear film lipid layer (TFLL). Ocul. Surf. 2013, 11, 236-245. [CrossRef] [PubMed]

50. Hetman, Z.A.; Borchman, D. Concentration dependent cholesteryl-ester and wax-ester structural relationships and meibomian gland dysfunction. Biochem. Biophys. Rep. 2020, 21, 100732. [CrossRef]

51. Wydro, P. Sphingomyelin/phosphatidylcholine/cholesterol monolayers-analysis of the interactions in model membranes and Brewster Angle Microscopy experiments. Colloids Surf. B 2012, 93, 174-179. [CrossRef]

52. Demel, R.A.; Bruckdorfer, K.R.; van Deenen, L.L.M. Structural requirements of sterols for the interaction with lecithin at the air-water interface. Biochim. Biophys. Acta-Biomembranes 1972, 255, 311-320. [CrossRef]

53. Demel, R.A.; Geurts van Kessel, W.S.M.; van Deenen, L.L.M. The properties of polyunsaturated lecithins in monolayers and liposomes and the interactions of these lecithins with cholesterol. Biochim. Biophys. Acta-Biomembranes 1972, 266, 26-40. [CrossRef]

54. Videv, P.; Mladenov, N.; Andreeva, T.; Mladenova, K.; Moskova-Doumanova, V.; Nikolaev, G.; Petrova, S.D.; Doumanov, J.A. Condensing Effect of Cholesterol on hBest1/POPC and hBest1/SM Langmuir Monolayers. Membranes 2021, 11, 52. [CrossRef] [PubMed]

55. Mangiarotti, A.; Galassi, V.V.; Puentes, E.N.; Oliveira, R.G.; del Pópolo, M.G.; Wilke, N. Hopanoids Like Sterols Form Compact but Fluid Films. Langmuir 2019, 35, 9848-9857. [CrossRef] [PubMed]

56. Jurak, M. Thermodynamic Aspects of Cholesterol Effect on Properties of Phospholipid Monolayers: Langmuir and LangmuirBlodgett Monolayer Study. J. Phys. Chem. B 2013, 117, 3496-3502. [CrossRef] [PubMed]

57. Cheyne, R.B.; Moffitt, M.G. Novel Two-Dimensional "Ring and Chain” Morphologies in Langmuir-Blodgett Monolayers of PS-b-PEO Block Copolymers: Effect of Spreading Solution Concentration on Self-Assembly at the Air-Water Interface. Langmuir 2005, 21, 5453-5460. [CrossRef]

58. Hung, W.-C.; Lee, M.-T.; Chen, F.-Y.; Huang, H.W. The Condensing Effect of Cholesterol in Lipid Bilayers. Biophys. J. 2007, 92, 3960-3967. [CrossRef]

59. Gong, K.; Feng, S.S.; Go, M.L.; Soew, P.H. Effects of pH on the stability and compressibility of DPPC/cholesterol monolayers at the air-water interface. Colloids Surf. A 2002, 207,113-125. [CrossRef]

60. Miyoshi, T.; Kato, S. Detailed Analysis of the Surface Area and Elasticity in the Saturated 1,2-Diacylphosphatidylcholine/Cholesterol Binary Monolayer System. Langmuir: The ACS J. Surf. Colloids 2015, 31, 9086-9096. [CrossRef]

61. Redlich, O.; Kister, A.T. Algebraic Representation of Thermodynamic Properties and the Classification of Solutions. Ind. Eng. Chem. 1948, 40, 345-348. [CrossRef]

62. Bonales, L.J.; Martínez-Pedrero, F.; Rubio, M.A.; Rubio, R.G.; Ortega, F. Phase Behavior of Dense Colloidal Binary Monolayers. Langmuir 2012, 28, 16555-16566. [CrossRef]

63. Guzman, E.; Orsi, D.; Cristofolini, L.; Liggieri, L.; Ravera, F. Two-Dimensional DPPC Based Emulsion-like Structures Stabilized by Silica Nanoparticles. Langmuir 2014, 30, 11504-11512. [CrossRef]

64. Hagen, J.P.; McConnell, H.M. Liquid-liquid immiscibility in lipid monolayers. Biochim Biophys Acta 1997, 1329, 7-11. [CrossRef]

65. Rowlinson, J.S.; Widom, B. The Molecular Theory of Capillarity; Clarendon Press: Oxford, UK, 1982.

66. Keller, D.J.; McConnell, H.M.; Moy, V.T. Theory of superstructures in lipid monolayer phase transitions. J. Phys. Chem. 1986, 90, 2311-2315. [CrossRef]

67. Gzyl-Malcher, B.; Handzlik, J.; Klekowska, E. Temperature dependence of the interaction of prazosin with lipid Langmuir monolayers. Colloids Surf. B 2013, 112, 171-176. [CrossRef] [PubMed] 
68. Benesch, M.G.K.; McElhaney, R.N. A comparative calorimetric study of the effects of cholesterol and the plant sterols campesterol and brassicasterol on the thermotropic phase behavior of dipalmitoylphosphatidylcholine bilayer membranes. Biochim. Biophys. Acta-Biomembranes 2014, 1838, 1941-1949. [CrossRef] [PubMed]

69. De Meyer, F.; Smit, B. Effect of cholesterol on the structure of a phospholipid bilayer. Proc. Nat. Acad. Sci. 2009, 106, 3654-3658. [CrossRef] [PubMed]

70. Baoukina, S.; Mendez-Villuendas, E.; Tieleman, D.P. Molecular View of Phase Coexistence in Lipid Monolayers. J. Am. Chem. Soc. 2012, 134, 17543-17553. [CrossRef] [PubMed]

71. Lopez-Rodriguez, E.; Pérez-Gil, J. Structure-function relationships in pulmonary surfactant membranes: From biophysics to therapy. Biochim. Biophys. Acta-Biomembr. 2014, 1838, 1568-1585. [CrossRef]

72. Bernardino de la Serna, J.; Perez-Gil, J.; Simonsen, A.C.; Bagatolli, L.A. Cholesterol rules: Direct observation of the coexistence of two fluid phases in native pulmonary surfactant membranes at physiological temperatures. J. Biol. Chem. 2004, 279, 40715-40722. [CrossRef] [PubMed] 